A.O. Frolova

\title{
ENERGY COMPONENTS OF GAS-LIQUID FLOW IN AEROTANK
}

\section{СОСТАВЛЯЮЩИЕ}

ГАЗОЖИДКОСТНОГО ПОТОКА В АЭРОТЕНКЕ

\begin{abstract}
Рассмотрены основные процессы гидродинамического режима работы аэротенка: образование и всплытие пузырьков воздуха при аэрации и движение водно-иловой смеси. Представлены формулы для определения потенциала скорости пузырька воздуха при аэрации и энергии потока движения водно-иловой смеси.
\end{abstract}

Ключевые слова: аэротенк, активный ил, гидродинамический режим, движение водно-иловой смеси, мицеллы, стесненные условия, потенциал скорости пузырька, формула Бьенкерса, уравнение Бернулли.
In the article the main processes of hydrodynamic regime of aeration tank are observed: the formation and ascent of air bubbles during aeration and motion of the water-sludge mixture. The formulas for determining the potential speed of an air bubble during aeration and energy of the water-sludge stream motion are presented. The investigation of interaction mechanism of purified waste water and air bubbles in the process of aeration in relation to the flow dynamics is poorly explored and challenging. Interaction of energetic components of the bubbles flow during aeration and uniform stream motion in the aerotank is the part of mass transfer and diffusion. The increase in total energy of the system by means of summing and raising potentials of the stream and bubbles speed can lead to increasing the purification effect, that means speeding up the diffusion processes.

Key words: aeration tank, activated sludge, hydrodynamic regime, water-sludge mixture motion, micelles, cramped conditions, potential speed of a bubble, the formula Benkers, Bernoulli equation.

Биохимическая очистка сточных вод является эффективным и перспективным процессом. Она осуществляется технически двумя способами: в аэротенках или биофильтрах. Происходящие в аэротенке процессы отличаются значительной сложностью, а их теоретическое изучение до сих пор нельзя назвать завершенным.

Условиями нормального протекания процесса биоокисления в аэротенке являются, во-первых, распределение хлопков активного ила более или менее равномерно во всем объеме сооружения, и, во-вторых, обеспечение переноса к ним растворенного кислорода и субстрата. В связи с этим в аэрационных сооружениях должен обеспечиваться некоторый уровень интенсивности перемешивания, достаточный для выполнения этих условий. На качество очистки влияет структура и состав активного ила и исходной сточной воды, а также гидродинамическая обстановка в сооружении.

Гидродинамический режим работы сооружения является составной частью процессов массопередачи и диффузии, однако при эксплуатации аэрационных сооружений неизбежно появление источников неоднородности поля концентраций в объеме, что связано с характером ввода поступающей воды и ила, а также с тем, что существующие системы аэрации по своим конструктивным особенностям таковы, что воздух и аэрируемая жидкость непосредственно контактируют лишь в отдельных областях объема сооружения. Исследование механизма взаимодействия потока очищаемой сточной воды и пузырьков воздуха при аэрации, с точки зрения гидродинамики, является малоизученным и поэтому весьма актуальным.

За образование определенной гидродинамической обстановки в аэрационном сооружении отвечают три процесса: образование пузырька воздуха, всплытие и движение водно-иловой смеси.

Образование пузырька происходит следующим образом: воздух поступает из отверстия (сопла) в виде отрывающихся пузырьков, в процессе всплытия будет происходить изменение их диаметров и форм от сферической к линзообразной и обратно под влиянием неравномерности распределения давления по контору пузыря. В процессе всплытия пузырек будет колебаться около вертикального направления (рис. 1) [1-3]. Эти колебания описываются дорожкой Кармана. 


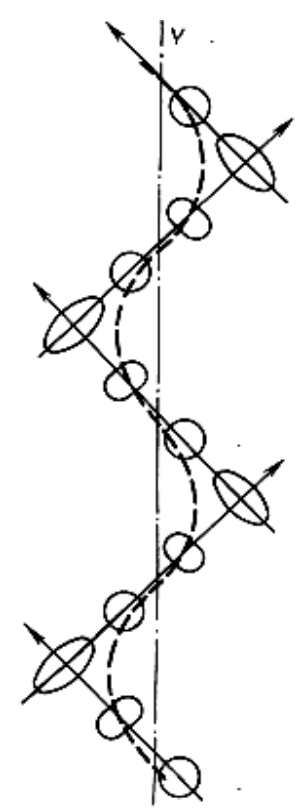

Рис. 1. Движение пузырька воздуха в жидкости

Однако в аэротенке происходит массовое всплытие пузырьков воздуха. Пузырьки в процессе всплытия двигаются в стесненных условиях. Стесненные условия движения частиц характеризуются закономерностями массового перемещения группы частиц, при котором каждая частица испытывает влияние окружающих частиц. При массовом всплытии пузырьков при аэрации наблюдается уменьшение отклонения колебаний пузырьков вокруг вертикального направления (рис. 2).

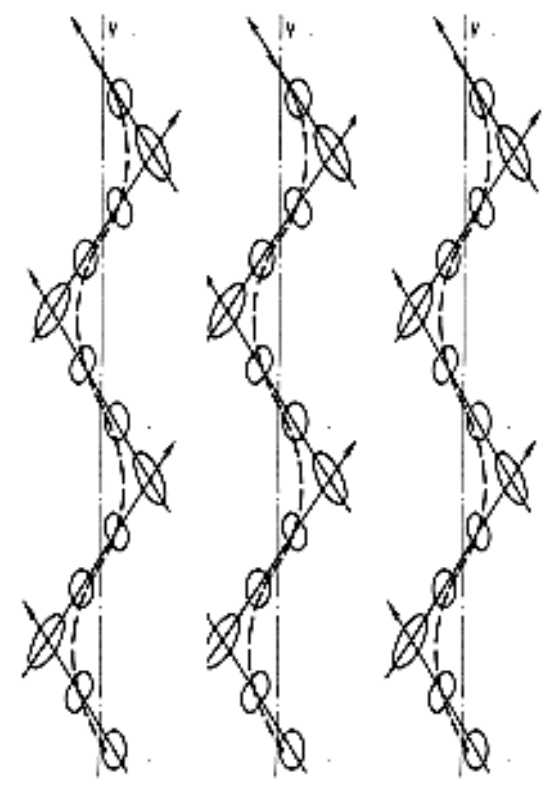

Рис. 2. Движение пузырьков в жидкости при их массовом всплытии

В результате литературных исследований [4-6] были сделаны выводы, что сточная вода и активный ил обладают свойствами коллоидов. В соответствии с коллоидной структурой активного ила и сточной воды в водно-иловой смеси образуются мицеллы. Представим обобщенный вид структуры модели хлопка активного ила в сточной воде, как это показано на рис. 3.

Движение пузырьков воздуха при аэрации и образовавшихся мицелл в сооружении происходит так же в стесненных условиях, т.е. мицеллы и пузырьки воздуха при движении испытывают влияние друг друга, что приводит к изменению траектории движения по сравнению с всплытием одиночного пузыря (рис. 4). 


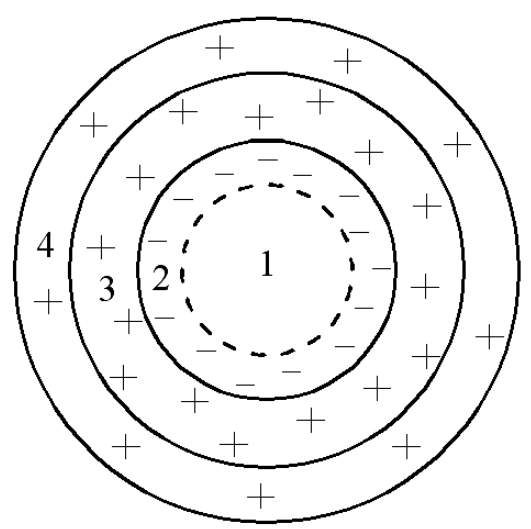

Рис. 3. Структура модели мицеллы: 1 - агрегат; 2 - ядро; 3 - адсорбционный слой; 4 - диффузионный слой
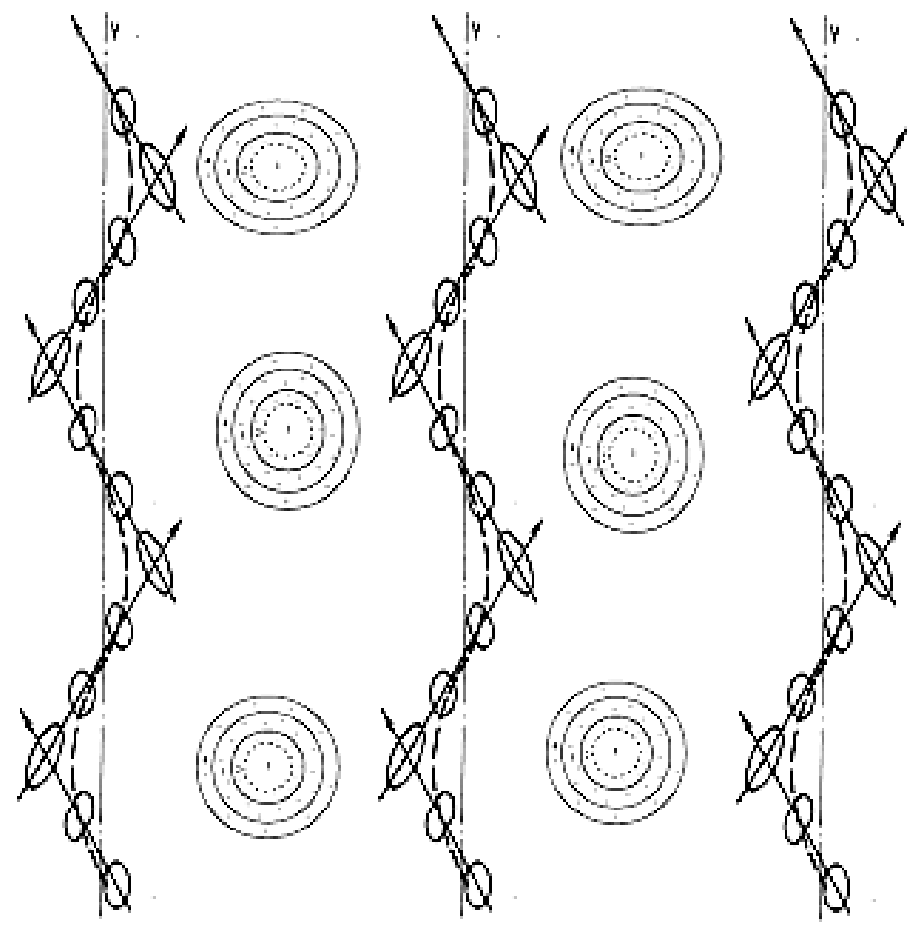

Рис. 4. Влияние массового всплытия пузырьков при аэрации на характер движения мицелл

Примем за основу для дальнейшего исследования закон сохранения энергии. Имея ввиду изменение траектории движения в воде (см. рис. 1), предположим, что для неподвижного пульсирующего источника (сферического пузырька) интенсивность которого $E(t)$ меняется со временем, а ось $x$ проходит через источник и его отображение, потенциал скорости вблизи источника определяется по формуле Бьенкерса [3, 7]:

$$
U=\left|-\frac{E(t)}{r}+\xi E(t) r \sin \alpha\right| \text {. }
$$

Решение данного уравнения применительно к нашим условиям выражается силой $U$ - внутренней энергией системы.

$$
U=\left|-\frac{E(t)}{r}+\xi\left(E(t) \sin \alpha+\frac{B(t) \sin \alpha}{2 r^{2}}\right)\right|,
$$

где $B(t)$ - момент диполя соответствующей поступательной скорости $b(t), B(t)=$ $=r^{2} b$, Кл·м; $E(t)$ - интенсивность колебаний пузырька, $E(t)=f(r) ; R$ - расстояние 
между отверстиями выпуска пузырьков воздуха, мм; $r$ - радиус пузырька, мм; для свободной поверхности коэффициент, учитывающий условия всплытия,

$$
\xi= \pm \frac{1}{4 R^{2}} \text { берется с «-», если граница считается свободной; }
$$

$b$ - скорость всплытия пузырьков воздуха, м/с.

Рассмотрение потоков движения воды в аэротенке показало, что на эффект очистки влияет структура потока, что актуально для расчета [8-10]. Скорости при движении воды в аэротенке в сходственных точках двух смежных сечений равны между собой, поэтому движение воды в аэротенке можно назвать равномерным. При этом условии все параметры движения и геометрические характеристики поперечного сечения должны быть неизменными вдоль всего потока, т.е. глубина $h$, площадь живого сечения $w$ и средняя скорость $V$ являются величинами постоянными. Движение воды в аэротенке весьма близко к описанному выше. Сделаем предположение, что течение в аэротенке является равномерным.

Тогда, применительно к реальному потоку рассчитать энергию потока можно по уравнению Бернулли:

$$
E_{\text {потока }}=\frac{P}{\rho g}+\frac{a V^{2}}{2 g},
$$

где $P$ - давление 10,33 м вод.ст.

Давление в сооружении

$$
P=10,33+\frac{h}{2},
$$

где $h$ - глубина воды в сооружении, м; $V$ - скорость движения жидкости, м/с; $\rho$ - плотность, кг $/ \mathrm{M}^{3} ; a-$ коэффициент Кориолиса.

$B$ blвод. Взаимодействие энергетических составляющих потока пузырьков воздуха при аэрации и равномерного движения потока воды в аэротенке является составляющей частью процессов массопередачи, диффузии. Повышение общей энергии системы за счет суммирования и увеличения потенциалов скоростей потока и пузырьков способно привести к повышению эффекта очистки, т.е. к ускорению процессов диффузии.

\section{БИБЛИОГРАФИЧЕСКИЙ СПИСОК}

1. Кутателадзе С.С., Стыринкович М.А. Гидродинамика газожидкостных систем М. : Энергия, 1976. 296 с. $136 \mathrm{c}$.

2. Попкович Г.С., Репин Б.Н. Система аэрации сточных вод. М. : Стройиздат, 1986.

3. Dankwerts P.V. Significance of Liquid-film Coefficients in gas absorption. Industrial and Engineering Chemistry. 1951, no. 6, vol. 43, pp. 1460-1467.

4. Гусев М.В. Микробиология. М., 2010. 464 c.

5. Вилкова Н.Г. Микробиология. Пенза, 1999. 100 с.

6. Michael H. Gerardi. Wastewater Bacteria 2006, published by John Wiley \& Sons, Hoboken, New Jersey.

7. Биркгоф Г., Сарантонелло Э. Струи, следы и каверны / под ред. Г.Ю. Степанова. М. : МИР, 1964. $466 \mathrm{c}$.

8. Кульков В.Н., Солопанов Е.Ю. Гидродинамика в аэротенке с пневматической аэрацией // Известия вузов. Строительство. 2010. № 7. С. 66-73.

9. Казаков В.Д., Пельменёва Н.Д. Экспериментальное исследование траекторий и скоростей движения жидкости на поверхности аэротенка // Вестник ИрГТУ. 2010. № 4(44). C. $87-90$.

10. Газогидродинамическая обстановка и распределение активного ила в сооружениях биологической очистки сточных вод / В.Н. Кульков, Е.Ю. Солопанов, И.В. Евтеева, А.С. Разум // Вестник ИрГТУ. 2008. № 4(36). С. 48-52.

\section{REFERENCES}

1. Kutateladze S.S., Styrinkovich M.A. Gidrodinamika gazozhidkostnykh sistem [Hydrodynamics of Gas-liquid Systems]. Moscow, Energiya Publ., 1976, 296 p.

2. Popkovich G.S., Repin B.N. Sistema aeratsii stochnykh vod [The System of Waste Water Aeration]. Moscow, Stroyizdat Publ., 1986, 136 p. 
3. Dankwerts P.V. Significance of Liquid-film Coefficients in Gas Absorption. Industrial and Engineering Chemistry. 1951, no. 6, vol. 43, pp. 1460-1467.

4. Gusev M.V. Mikrobiologiya [Microbiology]. Moscow, 2010, 464 p.

5. Vilkova N.G. Mikrobiologiya [Microbiology]. Penza, 1999, 100 p.

6. Michael H. Gerardi. Wastewater Bacteria. 2006, John Wiley \& Sons, Hobo-ken, New Jersey.

7. Birkgof G., Sarantonello E., edited by Stepanov G.Yu. Strui, sledy i kaverny [Streams, Tracks and Caverns]. Moscow, MIR Publ, 1964, 466 p.

8. Kul'kov V.N., Solopanov E.Yu. Gidrodinamika v aerotenke s pnevmaticheskoy aeratsiey [Hydrodynamics in Aerotank with Pneumatic Aeration]. Izvestiya vuzov. Stroitel'stvo [News of the Institutions of Higher Education. Construction]. 2010, no. 7, pp. 66-73.

9. Kazakov V.D., Pel'meneva N.D. Eksperimental'noe issledovanie traektoriy i skorostey dvizheniya zhidkosti na poverkhnosti aerotenka [Experimental Investigation of the Trajectories and Speed of Liquid Motion on the Surface of Aerotank]. Vestnik IrGTU [Proceedings of Irkutsk State Technical University]. 2010, no. 4(44), pp. 87-90.

10. Kul'kov V.N., Solopanov E.Yu., Evteeva I.V., Razum A.S. Gazogidrodinamicheskaya obstanovka i raspredelenie aktivnogo ila v sooruzheniyakh biologicheskoy ochistki stochnykh vod [Gashydrodynamic State and Distribution of Activated Sludge in the Structures of Biological Wastewater Treatment Vestnik IrGTU [Proceedings of Irkutsk State Technical University]. 2008, no. 4(36), pp. $48-52$.

Поступила в редакцию в октябре 2013 г.

Об авторе: Фролова Анна Олеговна - аспирант кафедры водоотведения и водной экологии, ФГБОУ ВПО «Московский государственный строительный университет» (ФГБОУ ВПО «МГСУ»), 129337, г. Москва, Ярославское шоссе, д. 26, frolova_a_o@mail.ru.
About the author: Frolova Anna Olegovna postgraduate student, Department of Water Discharge and Aquatic Ecology, Moscow State University of Civil Engineering (MGSU), 26 Yaroslavskoe shosse, Moscow, 129337, Russian Federation; frolova_a_o@mail.ru.

Для цитирования:

Фролова А.О. Энергетические составляющие газожидкостного потока в аэротенке [Электронный ресурс] // Строительство: наука и образование. 2013. Вып. 3. Ст. 5. Режим доступа: http://www.nso-journal.ru.

For citation:

Frolova A.O. Energeticheskie sostavlyayushchie gazozhidkostnogo potoka $\mathrm{v}$ aerotenke [Energy Components of Gas-Liquid Flow in Aerotank]. Stroitel'stvo: nauka i obrazovanie [Construction: Science and Education]. 2013. no. 3, paper 5. Available at: http://www.nso-journal.ru. 